\title{
Severe Hyperuricemia, Hepatic Steatosis and Dyslipidemia in Younger Patients with Tophaceous Gout
}

\section{Zheng Wuyan ${ }^{1}$, Chen Jianchun ${ }^{2}$, Lv Wanping ${ }^{3}$, Tan Wei $^{4}$ and Oshmianska Nataliia ${ }^{*}$}

${ }^{1}$ Scientific Research Department, Chengdu Rheumatism Hospital, China

${ }^{2}$ Rheumatology Department 1, Chengdu Rheumatism Hospital, China

${ }^{3}$ Rheumatology Department, Chengdu Rheumatism Hospital, China

${ }^{4}$ Surgical Department, Chengdu Rheumatism Hospital, China

*Corresponding Author: Oshmianska Nataliia, Scientific Research Department, Chengdu Rheumatism Hospital, China.
Received: April 24, 2021

Published: May 11, 2021

(C) All rights are reserved by Oshmianska

Nataliia., et al.

\begin{abstract}
Introduction: Despite gout being widely known as the disease of old age, recent studies showed the rising problem of hyperuricaemia in children and young adults. Our aim was to analyze the factors influencing tophi formation in gout patients younger than 45 years old with major functional impairment of the joint.

Subjects and Methods: This study retrospectively analyzed medical records of 280 male patients between 18 and 80 years old (including 108 patients aged below 45) who were admitted in 2019-2020 with complains for major functional impairment of the joints and/or massive joint transformation and diagnosed with gout. The frequency of renal and hepatic disorders, presence of hepatic steatosis was assessed as well as lipid profile.

Results: Younger patients with disabling tophaceous gout have significantly higher serum uric acid compared to those aged above 60 and higher rate of hepatic steatosis, significantly higher triglycerides $(2.62 \pm 2.49 \mathrm{mmol} / \mathrm{L}$ compared to $1.75 \pm 1.02)$ and higher total cholesterol. There was a trend for lower HDL cholesterol and higher LDL cholesterol ( $\mathrm{r}=0.116$ and -0.119 respectively). Frequency of hypertriglyceridemia in younger gout patients was $39.81 \%$, which is significantly higher compared to patients older than $60(17.31 \%)$.

Conclusion: We found that young patients with tophaceous gout have significantly higher levels of hyperuricemia compared to patients older than 60. Rate of hepatic steatosis and dyslipidemia was also higher in younger patients, which may contribute to the development of metabolic syndrome and lead to tophi formation and major functional impairment of the joints in the very young age. Keywords: Uric Acid; Hyperuricemia; Metabolic Syndrome; Gout; Hyperlipidemias; Gouty Arthritis
\end{abstract}

\section{Introduction}

Inadequate purine metabolism resulting in hyperuricemia and gout may considerably lower the patients' quality of life. In addition to that, gout is often combined with hypertension, obesity, resistance to insulin and other manifestations of a metabolic syndrome [1].

Risk factors for gout and hyperuricaemia include increasing age [2], alcohol consumption [3] and elevated body mass index (BMI)
[4]. Despite the fact that gout is widely known as the disease of older age, recent studies showed the rising problem of hyperuricaemia in children and young adults [5], pronounced hyperuricaemia in gout patients of younger generation [6].

Clinically hyperuricemia often co-exists with kidney and liver diseases, increasing the incidence of gout and aggravating the symptoms in gout patients. Ability of excessive uric acid (UA) to induce kidney stones, interstitial nephritis, acute or chronic renal 
dysfunction leads to increase in the burden of kidney filtration in gout patients, aggravation of the clinical symptoms of gout $[7,8]$. Patients with gout or hyperuricemia were found to be in a higher risk of developing cardiovascular and liver diseases [9] and reducing the serum uric acid levels can effectively improve the effectiveness of cardiovascular treatment [10].

Lipid profiles have been found to have a stronger association with serum UA in younger gout patients than other components of metabolic syndrome [11]. The role of single lipid species in promoting hyperuricemia remains mostly unclear [12], with some recent studies showing conflicting data in different populations $[13,14]$. On the other hand, recent study by Ni Qing., et al. [15] conducted in 2019 showed that higher BMI and high levels of LDL increase the risk of hyperuricemia.

However, studies focused on development of gout in patients younger than 45 years old are rare. A better understanding of the link between chronic inflammatory diseases such as gout and metabolic syndrome, renal and hepatic disorders in younger patients can provide valuable insights into their mechanisms and help the development of timely targeted interventions to reduce the risk of early disability and incapacity for working.

\section{Aim of the Study}

Thus, our study aimed to analyze the factors influencing tophi formation in gout patients younger than 45 years old with major functional impairment of the joint and/or massive joint transformation.

\section{Materials and Methods}

This retrospective study analyzed medical records of 386 male patients between 18 and 80 years old (as of August 2020) were analyzed for the purposes of current study. All patients were admitted to Chengdu Rheumatism Hospital in 2019 - 2020 and satisfied the preliminary criteria of gout. Patients were divided into 3 groups: aged below 45 (Group 1), aged from 45 to 59 (Group 2) and aged over 60 (Group 3). The study was approved by the Ethics Committee of Chengdu Rheumatism Hospital. Due to the retrospective nature of this study there was no need for consent to participate.

After initial analysis subjects with diabetes mellitus and those who ceased smoking recently were excluded from the study. Remaining subjects were divided on the groups according to their age and groups were adjusted by mean BMI. The exclusion of diabetes mellitus was based on the reports that this condition affects the serum lipids independently, and recent smoking cessation was reported to affect serum UA levels.
Data collection: In all patients, anthropometrical parameters were measured, including waist circumference, body height and weight, body mass index (BMI). In addition, blood pressure at systolic and diastolic phases, fasting serum glucose and creatinine were measured. Serum UA was measured on the first day and after the end of treatment by standard ELISA method. Presence of hepatic steatosis was assessed by B-ultrasonography, in some cases with additional MRI or liver biopsy. The diagnosis of renal dysfunction was based on serum creatinine and glomerular filtration rate; kidney stones was detected by X-ray and B-ultrasonography.

Lipid profile: Total cholesterol, HDL and LDL fractions, triglycerides have been measured by standard ELISA method. Following standards of Chengdu Rheumatism Hospital based on the National guidelines were used for the definition of elevated (or lowered): triglycerides $\geq 2.3 \mathrm{mmol} / \mathrm{L}$; total cholesterol $\geq 5.6 \mathrm{mmol} / \mathrm{L}$; HDL $\leq$ $0.9 \mathrm{mmol} / \mathrm{L}$; LDL 0 - $4.11 \mathrm{mmol} / \mathrm{L}$.

\section{Statistical analysis}

Baseline characteristics of participants were evaluated by descriptive statistics and results were presented in the form of mean \pm standard deviation. Comparisons in the means of continuous variables with a normal distribution were performed by using Student's t-test. Comparisons in medians of continuous variables with a skewed distribution were performed by using a Wilcoxon ranksum test. All reported probability values (P-values) were based on two-sided tests and $\mathrm{P}$ value $<0.05$ was considered statistically significant. The risk factors and odds ratio (OR) for developing high LDL cholesterol, low HDL cholesterol and hypertriglyceridemia were evaluated. Statistical analysis was conducted using IBM IPSS statistics software (version 23, IBM Co., Armonk, NY, USA).

\section{Results}

Total of 280 patients with gout were included in this study. All patients were of male gender, more than one third younger than 45 (38.57\%, $\mathrm{N}=108)$. It is important to note, that despite severe gout is considered mostly the disease of older generation, there was a reasonable amount of younger patients in our hospital with disabling deformations of joints and big tophi, who benefited from the surgical treatment.

Comparing to other two groups (45 - 60 and especially those over 60 years old) younger patients had a higher BMI before adjustment and significantly higher serum UA ( $p<0.05)$. In most cases, complains upon admittance to the hospital for this group of patients were pain and discomfort in enlarged joints, inability to perform daily work. After accessing pain levels, $40.0 \%$ of younger patients reported pain leveled 6 or higher on VAS score, which was 
more often, compared to patients aged 45 - 60 (26.66\%) and older than $60(23.07 \%)$.

Smoking was more common in older patients $(63.46 \%$ compared to 52.88), but the number of heavy smokers who admitted to having this habit for more than 10 years was almost the same in every age group.

Almost half of all patients who were younger than 45 had been diagnosed with hepatic steatosis (44.44\%), which was statistically more often compared to patients older than 60 , even after adjustment for BMI. Other general characteristics of study patients are described in table 1.

\begin{tabular}{|c|c|c|c|c|}
\hline \multicolumn{2}{|c|}{ Factor } & $\begin{array}{c}\text { Group } 1 \\
\text { (Age } \leq 45), \\
n=108\end{array}$ & $\begin{array}{c}\text { Group } 2 \\
(45-59), \\
n=120\end{array}$ & $\begin{array}{c}\text { Group } 3 \\
\text { (Age } \geq 60 \text { ), } \\
n=52\end{array}$ \\
\hline \multicolumn{2}{|c|}{ BMI, $\mathrm{kg} / \mathrm{m}^{2}$} & $25.9 \pm 3.79$ & $\begin{array}{l}25.42 \pm \\
3.42\end{array}$ & $\begin{array}{l}24.12 \pm \\
3.02\end{array}$ \\
\hline \multicolumn{2}{|c|}{$\begin{array}{l}\text { Serum UA (before } \\
\text { treatment), } \mu \mathrm{mol} / \mathrm{L}\end{array}$} & $\begin{array}{c}562.79 \pm \\
141\end{array}$ & $\begin{array}{c}476.34 \pm \\
114.16\end{array}$ & $\begin{array}{l}462.1 \pm \\
317.29\end{array}$ \\
\hline \multicolumn{2}{|c|}{$\begin{array}{l}\text { Serum UA (after } \\
\text { treatment), } \mu \mathrm{mol} / \mathrm{L}\end{array}$} & $\begin{array}{c}341.66 \pm \\
93.2\end{array}$ & $\begin{array}{c}308.1 \pm \\
102.07\end{array}$ & $\begin{array}{l}102.5 \pm \\
100.32\end{array}$ \\
\hline \multirow[t]{3}{*}{$\begin{array}{l}\text { Smoking } \\
\text { status }\end{array}$} & $\begin{array}{c}\text { Never } \\
\text { smoked }\end{array}$ & 47.22 & 50.0 & 36.54 \\
\hline & $\begin{array}{c}\text { Smoked }< \\
10 \text { years }\end{array}$ & 15.74 & 6.67 & 3.85 \\
\hline & $\begin{array}{l}\text { Smoked > } \\
10 \text { years }\end{array}$ & 29.63 & 40.0 & 34.62 \\
\hline \multicolumn{5}{|c|}{$\begin{array}{l}\text { Accompanying diseases and conditions (prevalence rate, } \\
\% \text { ) }\end{array}$} \\
\hline \multicolumn{2}{|c|}{ Hypertension } & 7.41 & 26.67 & 48.08 \\
\hline \multicolumn{2}{|c|}{ Hepatic steatosis } & 44.44 & 42.5 & 21.15 \\
\hline \multicolumn{2}{|c|}{ Hyperlipidemia } & 27.78 & 20.0 & 21.15 \\
\hline \multicolumn{2}{|c|}{ Hepatic dysfunction } & 20.37 & 15.0 & 9.61 \\
\hline \multicolumn{2}{|c|}{ Renal dysfunction } & 9.26 & 19.17 & 40.38 \\
\hline \multicolumn{2}{|c|}{ Kidney stones } & 26.85 & 33.33 & 23.08 \\
\hline
\end{tabular}

Table 1: General characteristics of gout patients depending on age.

BMI: Body Mass Index; UA: Uric Acid.

Routine laboratory tests were performed, including ESR and CRP, but the range of variation amongst the data was too wide.
Levels of CRP before the treatment were elevated in almost all patients (median $21.07(0.05,219.42) \mathrm{mg} / \mathrm{L})$, regardless of the age. Urate lowering therapy notably reduced the levels of CRP to 10.69 $(0.12,115.47) \mathrm{mg} / \mathrm{L}$ in Group 1 and to $13.96(0,114) \mathrm{mg} / \mathrm{L}$ in Group 2. In patients of Group 3 (older than 60) after treatment levels of CRP were higher, but due to the wide range of variations there was no statistical significance noted (median 26.89 (0, 230.11) mg/L; $\mathrm{p}>0.05)$.

After analyzing lipid profiles, it was found that triglycerides and total cholesterol were significantly higher in young gout patients (Table 2). There was a trend for lower HDL cholesterol and higher LDL cholesterol in younger patients $(r=0.116$ and -0.119 respectively). Frequency of hypertriglyceridemia in younger gout patients was $39.81 \%$, which is significantly higher compared to patients older than 60 (17.31\%).

\begin{tabular}{|c|c|c|c|}
\hline Factor & $\begin{array}{l}\text { Group } 1 \text { (Age } \\
\leq 45 \text { ), } n=108\end{array}$ & $\begin{array}{c}\text { Group } 2 \\
(45-59), n \\
=120\end{array}$ & $\begin{array}{c}\text { Group } 3 \\
\text { (Age } \geq 60 \text { ), } \\
n=52\end{array}$ \\
\hline $\begin{array}{l}\text { Fasting blood } \\
\text { glucose }(\mathrm{g} / \mathrm{dL})\end{array}$ & $5.32 \pm 1.89$ & $5.22 \pm 1.29$ & $5.36 \pm 1.23$ \\
\hline $\begin{array}{l}\text { Triglyceride } \\
\text { (mg/dL) }\end{array}$ & $2.62 \pm 2.49$ & $2.42 \pm 2.03$ & $1.75 \pm 1.02$ \\
\hline $\begin{array}{c}\text { Total cholesterol } \\
(\mathrm{mg} / \mathrm{dL})\end{array}$ & $4.41 \pm 1.25$ & $4.19 \pm 1.02$ & $4.06 \pm 0.95$ \\
\hline $\begin{array}{l}\text { HDL cholesterol } \\
(\mathrm{mg} / \mathrm{dL})\end{array}$ & $0.97 \pm 0.27$ & $1.03 \pm 0.3$ & $1.05 \pm 0.29$ \\
\hline $\begin{array}{l}\text { LDL cholesterol } \\
\text { (mg/dL) }\end{array}$ & $2.88 \pm 0.78$ & $2.65 \pm 0.77$ & $2.58 \pm 0.83$ \\
\hline
\end{tabular}

Table 2: Fasting glucose and lipid profile of gout patients depending on their age.

\section{Discussion}

Gout is often accompanied by impaired glucose metabolism, hypertension, hyperlipidemia and NAFLD. Our study aimed to analyze the factors influencing tophi formation in gout patients younger than 45 years old with major functional impairment of the joint and/or massive joint transformation.

To the best of our knowledge it is the first big study undertaken on the patients of the same hospital which shows wide gap in the frequency of NAFLD and hypertriglyceridemia between gout 
patients of different generations. We found that younger patients with disabling tophaceous gout have significantly higher serum uric acid compared to those aged above 60 and higher rate of hepatic steatosis, higher triglycerides $(2.62 \pm 2.49 \mathrm{mmol} / \mathrm{L}$ compared to $1.75 \pm 1.02$ ) and higher total cholesterol. There was a trend for lower HDL cholesterol and higher LDL cholesterol $(r=0.116$ and -0.119 respectively). Frequency of hypertriglyceridemia in younger gout patients was $39.81 \%$, which is significantly higher compared to patients older than $60(17.31 \%)$.

Kuo., et al. [16] in the big cohort study of 39111 patients with gout and 39111 matched controls identified that risks for comorbidity with cardiovascular and liver diseases were higher in patients with gout (HR of 1.13 (1.08 to 1.18; p < 0.001). Kuwabara., et al. [17] in recent five-year cohort study showed that elevated serum UA increases the risk for developing high LDL cholesterol, as well as hypertriglyceridemia. It is well known that higher serum UA is associated with the worsening of metabolic profile and associated with higher BMI, blood pressure, fasting plasma glucose, fasting immunoreactive insulin, insulin resistance, hypertriglyceridemia and the number of other metabolic syndrome components [18].

In previous works we noted that frequency of metabolic syndrome and its components was lower in our patients, compared to other studies. But after including a bigger number of young patients with pronounced gout we found that frequency of hypertriglyceridemia and liver steatosis in gout patients younger than 45 is significantly higher compared to patients older than 60 , which should be taken into account for further works. For comparison, overall prevalence of NAFLD in Asia is $29.62 \%$. The prevalence rate is lowest in Japan (22.28\%), the highest in Indonesia (51.04\%), and about $29.81 \%$ in mainland China [19]. It is known, that serum UA and metabolic syndrome is much more closely related in females than in males, with young females ( $\leq 44$ years old) with hyperuricemia had the highest risk [6].

Serum UA plays an important role in lipogenesis and regulation of cholesterol. For example, recent study by Kuwabara., et al. [17] showed that high levels of serum UA was an independent predictor for the development of high LDL-cholesterol and hypertriglyceridemia. In our study we also found consistent link between increase in serum UA, increase in triglycerides/ LDL and decrease in HDL as shown on figure 1 ( $r=0.188$ for triglycerides, -0.199 and 0.139 for LDL and HDL respectively).

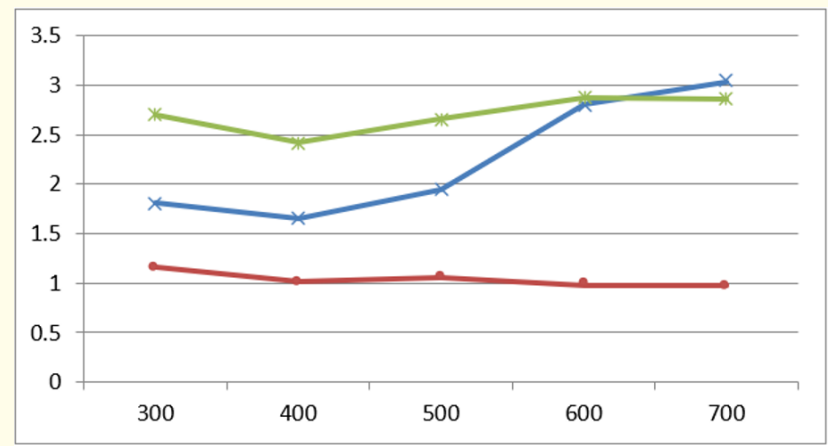

Figure 1: LDL (green), HDL (red) and triglycerides (blue) in dependence to serum uric acid increase, per every $100 \mu \mathrm{mol} / \mathrm{L}$.

Both in our previous works and current study we noted the inverse correlation between age and serum UA ( $r=-0.354)$. Thus, younger patients with gout more often have higher levels of serum UA, which may be the key to the dyslipidemia. Could notably higher frequency of NAFLD (almost half of all gout patients with disabling tophi under 45 ) be simply explained by that? Or in some cases preexisting NAFLD and metabolic syndrome led to gout?

In physiological conditions UA is a strong reactive oxygen species scavenger and antioxidant [20] and plays fundamental role in tissue healing, scavenging oxygen free radicals, and mobilizing progenitor endothelial cells. Additionally, UA attenuates nitric oxide (NO) production by influencing the interaction between endothelial NO synthase and calmodulin [21]. Under conditions of low $\mathrm{pH}$ and hypoxia elevated serum UA leads to excessive inflammation via NLRP3 pathway [21,22] and can promote the formation of superoxide anion and NO by the NADH oxidase. The NLRP3 inflammasome drives the activation of caspase-1, leading to the production of IL-1 $\beta$, IL-18, and a type of cell death termed pyroptosis [22].

Important to note, that aside from UA the NLRP3 inflammasome has been shown to sense other metabolites such as palmitate and cholesterol crystals [22,23]. NLRP3 is activated by various endogenous danger signals including those present in atherosclerotic 
lesions, such as oxidized low-density lipoprotein and cholesterol crystals. Recent study by Chuansheng Guo., et al. [23] showed that NLRP3 inflammasome activation is integrated with the maturation of cholesterol master transcription factor SREBP2, which is required for activation of the NLRP3 inflammasome both in vitro and in vivo. Enforced cholesterol biosynthetic signaling promoted NLPR3 inflammasome activation. Under hypoxic conditions UA adds to endothelial dysfunction by vascular insulin resistance associated with the impairment of NO synthesis [21] further fueling NLRP3 pathway.

All aforementioned data may partly explain the development of tophi and massive joint transformation in younger patients despite shorter duration of gout and shorter exposure to elevated UA. The pressing question is why younger gout patients in China have a higher incidence of NAFLD? Other studies already reported $[1,5,6]$ that metabolic syndrome is "getting younger", which means that its frequency is higher in younger generation following the higher BMI and different eating habits. In our study we also noted that dietary preferences reported by patients belonging to different generations sometimes were absolutely different, including the number of meals per day, calorage, amount of drinking water, etc. Conversely, 2019 study by Pascart., et al. [24] points out that gout with early onset might be primary, with following development of metabolic disorders. In any case, further studies are needed including wider assessment of NLRP3 mutations in gout.

\section{Limitation of the Study}

Our study had some limitations. Due to retrospective nature selection bias may exist, but all patients were observed by the same team of experienced rheumatologists. By design and other specifics we included only male patients of Chinese han origin, which may limit the results only to one sex and nationality. Another important thing is that patients belonging to different generations have understandable differences in the education level, life style and especially dietary preferences. It is without a doubt that the number and variety of patients in the study needs to be bigger for more precise data as to the association between age, tophi formation, hyperuricemia and metabolic syndrome.

\section{Conclusion}

In conclusion, we found that young patients with tophaceous gout have significantly higher levels of hyperuricemia compared to patients older than 60. Rate of hepatic steatosis and dyslipidemia was also higher in younger patients, which may contribute to the development of metabolic syndrome and lead to tophi formation and major functional impairment of the joints in the very young age.

\section{Supplement 1}

Risk factors for developing a) high LDL cholesterol, b) low HDL cholesterol, and c) hypertriglyceridemia over 5 years.

\begin{tabular}{|c|c|c|c|c|}
\hline \multicolumn{5}{|c|}{ a) High LDL cholesterol } \\
\hline & & OR & 95\%C.I. & $\mathbf{p}$ \\
\hline Age & $<45$ vs $>60$ & 1.47 & $1.09-4.64$ & 0.642 \\
\hline BMI & $<25$ vs $>25$ & 0.44 & $0.15-1.31$ & 0.13 \\
\hline Smoking & $\begin{array}{l}\text { Smokers vs non- } \\
\text { smokers }\end{array}$ & 0.52 & $0.17-1.56$ & 0.23 \\
\hline $\begin{array}{l}\text { Drinking } \\
\text { water }\end{array}$ & $\begin{array}{c}>2 \text { L/day vs > } 2 \\
\text { L/day }\end{array}$ & 0.61 & $0.21-1.77$ & 0.36 \\
\hline $\begin{array}{l}\text { Baseline } \\
\text { serum uric } \\
\text { acid }\end{array}$ & $\begin{array}{l}\text { Per } 100 \mu \mathrm{mol} / \mathrm{L} \\
\text { increase }\end{array}$ & 1.09 & $0.187-1.321$ & 0.14 \\
\hline \multicolumn{5}{|c|}{ b) Low HDL cholesterol } \\
\hline Age & $<45$ vs $>60$ & 2.84 & $0.985-1.164$ & 0.17 \\
\hline BMI & $<25$ vs $>25$ & 0.62 & $0.831-1.013$ & $<0.05$ \\
\hline Smoking & $\begin{array}{l}\text { Smokers vs non- } \\
\text { smokers }\end{array}$ & 1.62 & $0.970-2.707$ & 0.065 \\
\hline $\begin{array}{l}\text { Drinking } \\
\text { water }\end{array}$ & $\begin{array}{c}>2 \text { L/day vs > } 2 \\
\text { L/day }\end{array}$ & 1.05 & $0.647-1.706$ & 0.84 \\
\hline $\begin{array}{c}\text { Baseline } \\
\text { serum uric } \\
\text { acid }\end{array}$ & $\begin{array}{l}\text { Per } 100 \mu \mathrm{mol} / \mathrm{L} \\
\text { increase }\end{array}$ & 0.76 & $0.104-1.725$ & 0.48 \\
\hline \multicolumn{5}{|c|}{ c) Hypertriglyceridemia } \\
\hline Age & $<45$ vs $>60$ & 3.16 & $1.399-7.142$ & 0.004 \\
\hline BMI & $<25$ vs $>25$ & 0.79 & $0.476-1.299$ & 0.347 \\
\hline Smoking & $\begin{array}{l}\text { smokers vs non- } \\
\text { smokers }\end{array}$ & 1.29 & $0.770-2.190$ & 0.328 \\
\hline $\begin{array}{l}\text { Drinking } \\
\text { water }\end{array}$ & $\begin{array}{c}>2 \text { L/day vs }>2 \\
\text { L/day }\end{array}$ & 0.95 & $0.575-1.556$ & 0.836 \\
\hline $\begin{array}{l}\text { Baseline } \\
\text { serum uric } \\
\text { acid }\end{array}$ & $\begin{array}{l}\text { Per } 100 \mu \mathrm{mol} / \mathrm{L} \\
\text { increase }\end{array}$ & 0.71 & $0.935-2.101$ & 0.503 \\
\hline
\end{tabular}




\section{Bibliography}

1. Oh H., et al. "Comparisons of the Incidence and Critical Risk Factors of Metabolic Syndrome in Patients With a Rheumatic Disease or Gout". Orthopaedic Nursing 38.3 (2019): 201-208.

2. Wallace KL. "Increasing prevalence of gout and hyperuricemia over 10 years among older adults in a managed care population". The Journal of Rheumatology 31.8 (2004): 1582-1587.

3. Choi HK. "Alcohol intake and risk of incident gout in men: a prospective study". Lancet 363.94-17 (2004): 1277-1281.

4. Aune D., et al. "Body mass index and the risk of gout: a systematic review and dose-response meta-analysis of prospective studies". European Journal of Nutrition 53.8 (2014): 15911601.

5. Kubota M. "Hyperuricemia in Children and Adolescents: Present Knowledge and Future Directions". Journal of Nutrition and Metabolism (2019): 1-8.

6. Zhang Q., et al. "Gender and age impacts on the correlations between hyperuricemia and metabolic syndrome in Chinese". Clinical Rheumatology 30 (2011): 777-787.

7. Kuwabara M., et al. "Elevated Serum Uric Acid Level Predicts Rapid Decline in Kidney Function". Journal of the American Society of Nephrology 45.4 (2017): 330-337.

8. Mallat SG., et al. "Hyperuricemia, Hypertension, and Chronic Kidney Disease: an Emerging Association". Current Hypertension Reports 18.10 (2016): 74 .

9. Kuo CF., et al. "Comorbidities in patients with gout prior to and following diagnosis: case-control study". Annals of the Rheumatic Diseases 75 (2016): 210-217.

10. Zhang S., et al. "Hyperuricemia and Cardiovascular Disease". Current Pharmaceutical Design 25.6 (2019): 700-709.

11. Xu J., et al. "Associations of non-high density lipoprotein cholesterol and traditional blood lipid profiles with hyperuricemia among middle-aged and elderly Chinese people: a communitybased cross-sectional study". Lipids in Health and Disease 13.1 (2014): 117

12. Lippi G., et al. "Epidemiological association between uric acid concentration in plasma, lipoprotein(a), and the traditional lipid profile". Clinical Cardiology 33 (2010): 76-80.

13. Alikor C., et al. "Prevalence of hyperuricaemia in a rural population of Nigerian Niger Delta region". Nigerian Journal of Medicine 22 (2013): 187-192.

14. Mehrpour M., et al. "Serum uric acid level in acute stroke patients". The Medical Journal of the Islamic Republic of Iran 26 (2012): 66-72.
15. Ni Q., et al. "Risk factors for the development of hyperuricemia: A STROBE-compliant cross-sectional and longitudinal study". Medicine 98.42 (2019): e17597.

16. Kuo CF., et al. "Comorbidities in patients with gout prior to and following diagnosis: case-control study". Annals of the Rheumatic Diseases 75 (2016): 210-217.

17. Kuwabara M., et al. "Elevated serum uric acid increases risks for developing high LDL cholesterol and hypertriglyceridemia: A five-year cohort study in Japan". International Journal of Cardiology 261 (2018): 183-138.

18. Moriyama K. "Low-density Lipoprotein Subclasses are Associated with Serum Uric Acid Levels". Clinical Laboratory 64 (2018): 1137-1144.

19. Li J., et al. "Prevalence, incidence, and outcome of non-alcoholic fatty liver disease in Asia, 1999-2019: a systematic review and meta-analysis". The Lancet Gastroenterology and Hepatology 4.5 (2019): 389-398.

20. El Ridi R and Tallima H. "Physiological functions and pathogenic potential of uric acid: A review". Journal of Advanced Research 8.5 (2017): 487-493.

21. Otani N., et al. "Effects of uric acid on vascular endothelial function from bedside to bench". Hypertension Research 41.11 (2018): 923-931.

22. Hughes MM and O'Neill LAJ. "Metabolic regulation of NLRP3". Immunological Reviews 281.1 (2018): 88-98.

23. Guo C., et al. "Cholesterol Homeostatic Regulator SCAPSREBP2 Integrates NLRP3 Inflammasome Activation and Cholesterol Biosynthetic Signaling in Macrophages". Immunity 49.5 (2018): 842-856.

24. Pascart T., et al. "Patients With Early-Onset Gout and Development of Earlier Severe Joint Involvement and Metabolic Comorbid Conditions: Results From a Cross-Sectional Epidemiologic Survey". Arthritis Care and Research 71.7 (2019): 986-992.

\section{Assets from publication with us}

- Prompt Acknowledgement after receiving the article

- Thorough Double blinded peer review

- Rapid Publication

- Issue of Publication Certificate

- High visibility of your Published work

Website: www.actascientific.com/

Submit Article: www.actascientific.com/submission.php

Email us: editor@actascientific.com

Contact us: +919182824667 